\title{
Cluster based Optimization Routing Strategy for Data Communication in Mobile Computing
}

\author{
Faizul Navi Khan \\ Teerthanker Mahaveer \\ University \\ Moradabad, UP, INDIA
}

\author{
KapilGovil \\ Teerthanker Mahaveer \\ University \\ Moradabad, UP, INDIA
}

\begin{abstract}
Mobile computing facilitates users to keep the information handy and also continuous access to the application by using mobile computing devices (i.e. Smart phones, palmtop, laptop and tablets) without using wired network. It provides flexible communication to network users; they can access network applications anytime and anywhere. Communication between these devices and mobile network application is possible through the network routing. Network routing plays a significant role to improve the performance in Mobile computing. A routing algorithm is required to choose the communication path to travel data packets from source to destination in Mobile computing network. Routing in a mobile network typically involves a rather complex collection of algorithms that work more or less independently and yet support each other by exchanging services or information. In mobile communication network multiple data packets need to transmit in order to execute on available processing nodes with minimum transmission time. This research paper implies a cluster based routing strategy to help route data packets from source device to destination point.
\end{abstract}

\section{Keywords}

Data communication, Mobile Computing, Optimization technique, Routing Strategy

\section{INTRODUCTION}

Computer network change the face of computing, it facilitate multiple users can work together and access the same application at the same time. It was like boon for the business organization, government sectors and educational institutions. Initially a network was used fixed wired connections and it has some limitations in regards of locations. User should reach the location where network connected terminal is present, then only user was enabled to access network resources. Mobile computing break all these barriers due to the significant improvement in wireless technologies, it provides the facility continuous network connectivity to users regardless of their location. Data communication during the execution of any application between the processors in form of packets is a basic and primary activity in mobile computing. This activity is performed using a routing scheme, which is a mechanism working in a distributed fashion for routing data packets in Mobile computing.

In mobile computing routing defines a communication path for upcoming traffic of data packets for their execution in a minimum transmission time, in order to achieve better performance of mobile computing, routing strategy as efficient as possible. An application deals with the application data, the input data collects from the user's node and it communicate to processing node in mobile computing through a communication path chosen by the routing strategy.
Data in form of packets from originating source is pass across to destination processing node and execute or process on available resources using a server application and server execute those data packets and combine it to one piece of information and sent back to originating source in the form of result.

Network routing is common and challenging activity and it also play a vital role to improve the performance of Mobile Computing. Routing strategy becomes more critical when the multiple communication paths are present for data packets communication in a network. An effective routing strategy would be required to select most feasible communication path to transmit data packets in Mobile Computing for performance enhancement. This research paper focuses on the design of routing strategy that would make the arrangement of data routing by choosing the most suited path to data packets in a mobile computing where the numbers of data packets ' $\mathrm{m}$ ' will route on numbers of processors ' $n$ ' (where $m>n$ ). Routing strategy present in this research paper find the feasible path for application data packets to transmit at destination processing nodes, routing strategy will satisfy time constraint here, it means performance will measure in terms of transmission time or i.e. minimum transmission time and the problem discuss here is static in nature.

A problem of data communication in Mobile computing is considering here, where the multiple mobile users are accessing application running in the same network domain. An application is interact with processing nodes using data packets through communication path decided by the routing tables, Routing table is created by a routing algorithm to choose most appropriate route for data communication. In case multiple data paths exist for single data packets, routing strategy will decide feasible path to minimize transmission time for a data communication in mobile computing. Some of the routing algorithm and or methods have been reported in the literature, such as Routing Scheme [1, 2, 3, 5, 19, 20], Salesman Problem [4], Grid Computing [6, 8], Shortest paths in restricted graph [7], Task Allocation Scheme [9], Single system image [10], Performance and cost in a cloud computing system [11], Resource allocation policy [12], Job scheduling in mobile grids [13, 14], Enhancing the Overall Performance of Distributed Computing System [15], Remote execution for mobile computing [16] and Resource allocation scheme for mobile ad hoc computational grids $[17,18]$. This research paper introduces a routing strategy by implementing a routing algorithm to get maximum optimization of data communication that will also enhance the performance of mobile computing as well. 


\section{NOTATIONS}

$\begin{array}{ll}\mathrm{p} & \text { processing nodes } \\ \mathrm{d} & \text { data packet } \\ \mathrm{n} & \text { Number of Processors } \\ \mathrm{m} & \text { number of data packets } \\ \mathrm{TTM} & \text { Transmission Time Matrix } \\ \text { CTTM } & \text { Clustered Transmission Time } \\ \text { Matrix } & \end{array}$

\section{OBJECTIVE}

The main objective of this research paper is design a routing strategy to find a possible shortest communication path to transmit data packets from source to destination in mobile computing. An effective routing scheme is always helpful to improve the performance of mobile computing network. In client server architecture application data communicates between server and clients. Multiple data packets need to be transmits by using a communication path over mobile network. Routing table contains all possible communication path from each source to every destinations is called decision tables. Based upon the routing table, routing strategy chooses the feasible path in terms of transmission time to transmit a data packet. This research paper is solving the problem of network routing by optimizing routing strategies in data communication network of mobile computing. The nature of routing in data communication is static. Routing strategy will also ensure the delivery of all data packets at destination in optimize manner. In this paper performance is measured in term of transmission time of data packet.

\section{TECHNIQUE}

This research paper considers a scenario where a set $P=\left\{p_{1}\right.$, $\left.\mathrm{p}_{2}, \mathrm{p}_{3}, \ldots \ldots \ldots \mathrm{p}_{\mathrm{n}}\right\}$ of ' $\mathrm{n}$ ' processing nodes and a set $\mathrm{D}=\left\{\mathrm{d}_{1}, \mathrm{~d}_{2}\right.$, $\left.\mathrm{d}_{3}, \ldots \ldots \ldots \mathrm{d}_{\mathrm{m}}\right\}$ of ' $\mathrm{m}$ ' data packets originating from the different various sources in mobile computing. Each data packet has $n$ numbers of communication paths to go through for its execution or each data packet has an option to transmit on every processing node as per its feasibility. Transmission time are known for each data packets to every processing nodes in the network and it is stored in Transmission Time Matrix (TTM) of order $\mathrm{n} * \mathrm{~m}$. Communications between the data packets have also been taken into the consideration; it will be either 1 or 0 , where 1 represent communication between the data packets while 0 represent no communication. That is given in communication matrix namely CM (,) of order $\mathrm{m} \mathrm{x} \mathrm{m}$. Clusters for the data packets would be formed for each data packet based on the communication and the number of data packets in cluster will be $[\mathrm{m} / \mathrm{n}]$ in case $\mathrm{m}$ is even otherwise number of data packets will be $[\mathrm{m}+1 / \mathrm{n}]$ in a cluster. The employed routing strategy re-arrange the set of clusters and get $n$ number of ordered pair and none of the data packet will be repeated in a cluster. Minimum number of data packet in any cluster should be 1 , remaining ordered pair may not be considered. After these steps $n$ numbers of clusters are formed for $n$ numbers of processing nodes. Data clusters will be arrange in Cluster Transmission Time Matrix (CTTM), Column wise average will be calculated for each column. Calculated average is compared with CTTM in vertical manner for each element and search for the minimum value (transmission time) and route the data packet cluster to destination point. The process is repeated until all data cluster would be routed in mobile computing.

\section{ALGORITHM}

1. Start Algorithm
2. Read the number of data packets in $m$

3 . Read the number of processing nodes in $n$

4. Store Data packets and Transmission Time into Matrix TTM (,) in order of $\mathrm{m} x \mathrm{n}$.

5. Store Communication Matrix (,) in order of $\mathrm{m} \mathrm{x} \mathrm{m}$.

6. Based on Communication matrix formed data cluster having $\mathrm{m} / \mathrm{n}$ numbers of data packets

7. Clubbing the values of Data packets present in Data cluster and derived a new Cluster Transmission Time Matrix (CTTM) and also set routing status as false for each cluster. 8. Calculate average () for each Column in vertical manner 9. While (All data clusters! = routed)

\{

i. Find minimum value in vertical manner for each processing node

ii. Check routing status

iii. If routing status $=$ false

iv. Route the eligible data packet to available communication path and set routing status as TRUE.

v. Else \}

vi. search for next appropriate value

10. State the results

11. End of algorithm

\section{IMPLEMENTATION}

This research paper have considered mobile computing network which consist a set $\mathrm{P}$ of 3 processing nodes $\left\{\mathrm{p}_{1}, \mathrm{p}_{2}\right.$, $\left.\mathrm{p}_{3}\right\}$ with different processing capacity and a set D of 6 data packets $\left\{d_{1}, d_{2}, d_{3}, d_{4}, d_{5}, d_{6}\right\}$. Each data packet has multiple paths to transmit for their execution as mentioned in Fig. 1.

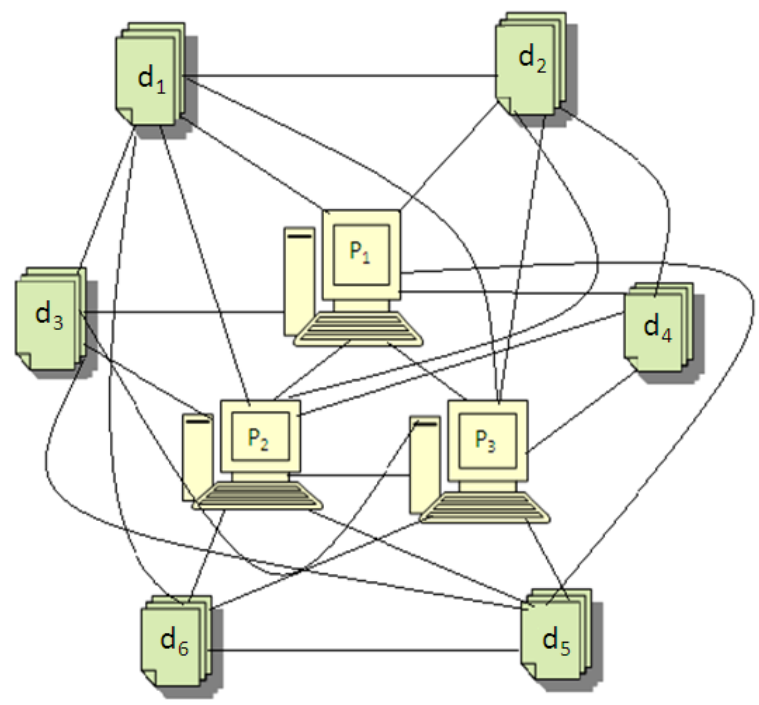

Fig. 1: Data and processing unit's communication graph

Transmission time of each data packet to each processing node are known and mentioned in the Transmission Time Matrix namely TTM [,] of order $\mathrm{m} \mathrm{x} \mathrm{n}$ as mentioned in Table I. 
Table I: Transmission Time Matrix

$\begin{array}{ccccc} & & \mathrm{p}_{1} & \mathrm{p}_{2} & \mathrm{p}_{3} \\ & \mathrm{~d}_{1} & 10 & 30 & 09 \\ \mathrm{~d}_{2} & 10 & 40 & 08 \\ \mathrm{~d}_{3} & 08 & 15 & 15 \\ \mathrm{~d}_{4} & 07 & 20 & 10 \\ \mathrm{~d}_{5} & 20 & 08 & 10 \\ \mathrm{~d}_{6} & 08 & 09 & 07\end{array}$

Communication between data packets have taken into the considerations as well and shown in Fig. 2.

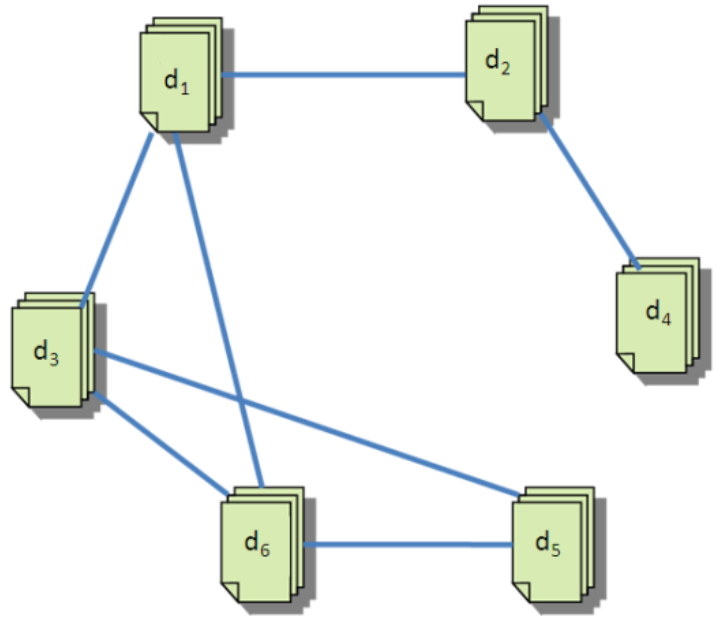

Fig. 2: Communication tree between data packets

Matrix representation of communication between data packets are mentioned in Communication Matrix namely CM [,] in order of $\mathrm{m} \mathrm{x} \mathrm{m}$.

Table II: Communication Matrix

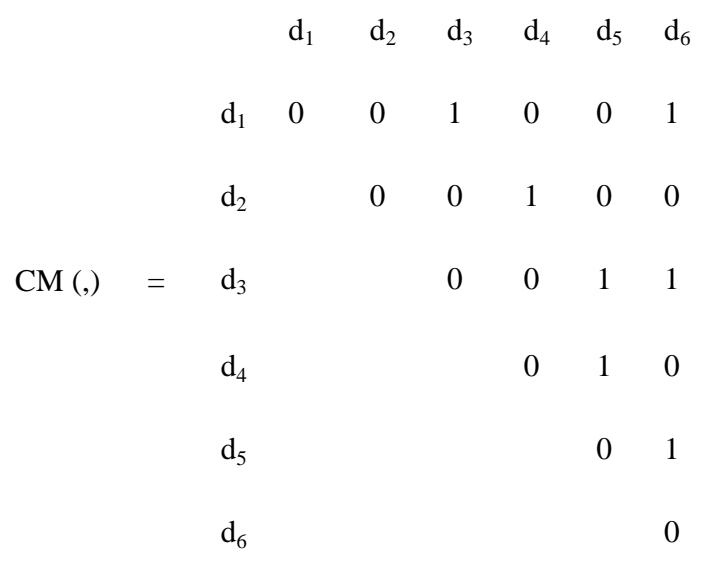

By considering communication matrix CM () as mentioned in Table II the following data packet clusters will form:

$\begin{array}{lll}\text { For data packet } \mathrm{d}_{1}: & & \left\{\left(\mathrm{d}_{1} * \mathrm{~d}_{3}\right),\left(\mathrm{d}_{1} * \mathrm{~d}_{6}\right)\right\} \\ \text { For data packet } \mathrm{d}_{2}: & & \left\{\left(\mathrm{d}_{2} * \mathrm{~d}_{4}\right)\right\} \\ \text { For data packet } \mathrm{d}_{3}: & & \left\{\left(\mathrm{d}_{3} * \mathrm{~d}_{5}\right),\left(\mathrm{d}_{3} * \mathrm{~d}_{6}\right)\right\} \\ \text { For data packet } \mathrm{d}_{4}: & \left\{\left(\mathrm{d}_{4} * \mathrm{~d}_{5}\right)\right\} \\ \text { For data packet } \mathrm{d}_{5}: & \left\{\left(\mathrm{d}_{5} * \mathrm{~d}_{6}\right)\right\} \\ \text { For data packet } \mathrm{d}_{6}: & -\end{array}$

From the above sets of clusters by neglecting repeated data packets or ordered pair, three final distinct data cluster would be select $\left(\mathrm{d}_{1} * \mathrm{~d}_{3}\right),\left(\mathrm{d}_{2} * \mathrm{~d}_{4}\right) \&\left(\mathrm{~d}_{5} * \mathrm{~d}_{6}\right)$ :

$$
\begin{aligned}
& \text { Cluster } \mathrm{Cl}_{1}-\left\{\mathrm{d}_{1} * \mathrm{~d}_{3}\right\} \\
& \text { Cluster } \mathrm{Cl}_{2}-\left\{\mathrm{d}_{2} * \mathrm{~d}_{4}\right\} \\
& \text { Cluster } \mathrm{Cl}_{3}-\left\{\mathrm{d}_{5} * \mathrm{~d}_{6}\right\}
\end{aligned}
$$

By considering the data cluster instead of single data packet will drive another matrix namely Cluster Transmission Time Matrix CTTM [,] from the TTM [,] these data clusters will also contain their routing status, initially set to false as

\begin{tabular}{|c|c|c|c|c|c|}
\hline & & Clusters & $\mathrm{p}_{1}$ & $\mathrm{p}_{2}$ & $\mathrm{p}_{3}$ \\
\hline & & $\underset{\text { routing=false }}{\mathrm{Cl}_{1}\left\{\mathrm{~d}_{1} * \mathrm{~d}_{3}\right\}}$ & 18 & 45 & 24 \\
\hline СTTM () & $=$ & $\begin{array}{l}\mathrm{Cl}_{2}\left\{\mathrm{~d}_{2} * \mathrm{~d}_{4}\right\} \\
\text { routing =false }\end{array}$ & 17 & 60 & 18 \\
\hline & & $\begin{array}{l}\mathrm{Cl}_{3}\left\{\mathrm{~d}_{5} * \mathrm{~d}_{6}\right\} \\
\text { routing =false }\end{array}$ & 28 & 17 & 17 \\
\hline
\end{tabular}
mentioned in Table III.

\section{Table III: Cluster Transmission Time Matrix}

As per the routing logic here, average will be computed for each column as mentioned in Table IV:

\section{Table IV: Showing average for each column}

$\begin{array}{llccc} & \text { Clusters } & \mathrm{p}_{1} & \mathrm{p}_{2} & \mathrm{p}_{3} \\ \mathrm{Cl}_{1}\left\{\mathrm{~d}_{1} * \mathrm{~d}_{3}\right\} & 18 & 45 & 24 \\ \text { routing=false } & & & \\ & \mathrm{Cl}_{2}\left\{\mathrm{~d}_{2} * \mathrm{~d}_{4}\right\} & 17 & 60 & 18 \\ \text { routing }=\text { false } & & & \\ & \mathrm{Cl}_{3}\left\{\mathrm{~d}_{5} * \mathrm{~d}_{6}\right\} & 28 & 17 & 17 \\ \text { routing =false } & & & \\ \text { Average } & 21 & 40 & 19\end{array}$

After compute the average for each column, average value will compare for each cell value in vertical manner and search for the minimum value, once that condition will match (i.e. average $<=$ Transmission time), with the routing status is false for matched data cluster, the data cluster will gets route and routing status will set to true to ensure that data cluster will not be consider in the next iteration, otherwise logic will search for next appropriate match. By following the same routing strategy two data cluster $\left(\mathrm{Cl}_{2}\left\{\mathrm{~d}_{2} * \mathrm{~d}_{4}\right\}\right.$ and $\mathrm{Cl}_{2}\left\{\mathrm{~d}_{5} *\right.$ $\left.\mathrm{d}_{6}\right\}$ ) will assign as mentioned in Routing Table $\mathrm{V}$.

\section{Table V: Routing Table}

$\begin{array}{ccc}\text { Processor } & \text { Clusters } & \text { Transmission Time } \\ \mathrm{p}_{1} & \mathrm{Cl}_{2}\left\{\mathrm{~d}_{2} * \mathrm{~d}_{4}\right\} & 17 \\ \mathrm{p}_{2} & \mathrm{Cl}_{3}\left\{\mathrm{~d}_{5} * \mathrm{~d}_{6}\right\} & 17\end{array}$

After the routing of two data cluster $\left(\mathrm{Cl}_{2}\left\{\mathrm{~d}_{2} * \mathrm{~d}_{4}\right\}, \mathrm{Cl}_{3}\left\{\mathrm{~d}_{5} *\right.\right.$ $\left.\left.\mathrm{d}_{6}\right\}\right)$, first data cluster $\left(\mathrm{Cl}_{1}\left\{\mathrm{~d}_{1} * \mathrm{~d}_{3}\right\}\right)$ still remain gets unrouted as mentioned Table VI: 
Table VI: $\mathrm{Cl}_{1}$ still remain unrouted

$\begin{array}{lllll}\text { Clusters } & \mathrm{p}_{1} & \mathrm{p}_{2} & \mathrm{p}_{3} \\ \mathrm{Cl}_{1}\left\{\mathrm{~d}_{1} *\right. & 18 & 45 & 24 \\ \left.\mathrm{~d}_{3}\right\}_{\text {routing=false }} & & & \\ \mathrm{Cl}_{2}\left\{\mathrm{~d}_{2} * \mathrm{~d}_{4}\right\} & 17 & 60 & 18 \\ \begin{array}{l}\text { routing=true } \\ \mathrm{Cl}_{3}\left\{\mathrm{~d}_{5} * \mathrm{~d}_{6}\right\}\end{array} & 28 & 17 & 17 \\ \text { routing=true } \\ \text { Average }\end{array}$

Although $\mathrm{p}_{3}$ processor has minimum value in row $2(18)$ and row 3 (17) with satisfying condition avg $<=\mathrm{p}_{\text {time }}$, But the data routing has already been done for these two rows as mentioned in Table VI. So finally data cluster $\left(\mathrm{Cl}_{1}\left\{\mathrm{~d}_{1} * \mathrm{~d}_{3}\right\}\right)$ will be route to $\mathrm{p}_{3}$ processor and final data communication path is mentioned in Table VII.

\section{Table VII: Routing Table}

$\begin{array}{ccc}\text { Processor } & \text { Clusters } & \text { Transmission Time } \\ \mathrm{p}_{1} & \mathrm{Cl}_{2}\left\{\mathrm{~d}_{2} * \mathrm{~d}_{4}\right\} & 17 \\ \mathrm{p}_{2} & \mathrm{Cl}_{3}\left\{\mathrm{~d}_{5} * \mathrm{~d}_{6}\right\} & 17 \\ \mathrm{p}_{3} & \mathrm{Cl}_{1}\left\{\mathrm{~d}_{1} * \mathrm{~d}_{3}\right\} & 24\end{array}$

\section{CONCLUSION}

The problem is discussed in this research paper provides an optimal data communication solution in a mobile computing network to minimize transmission time between data packets to each processing nodes with the proper utilization of available resources. This research paper has demonstrated $\mathrm{m}$ numbers of data packets need to transmit to $n$ numbers of processing nodes where $m$ is always greater than $n$ in mobile computing network. This approach forms data clusters before routing, it make the process simple and optimize. The technique stated in pseudo code applied on several sets of input data and that verified the objective of get minimum transmission time for given data packets for their execution. Here performance is measured in terms of transmission time of the data packets that has been executed by the processing nodes of the mobile computing network. The outcome of the given example as mentioned in Table VIII:

Table VIII: Resulting routing table of given example

Processor

$$
\text { Data packets }
$$

Transmission Time

\begin{tabular}{ccc}
$\mathrm{p}_{1}$ & $\mathrm{~d}_{2} * \mathrm{~d}_{4}$ & 17 \\
$\mathrm{p}_{2}$ & $\mathrm{~d}_{5} * \mathrm{~d}_{6}$ & 17 \\
$\mathrm{p}_{3}$ & $\mathrm{~d}_{1} * \mathrm{~d}_{3}$ & 24 \\
\multicolumn{2}{c}{ Total Transmission Time } & 48
\end{tabular}

Fig. 3 shows the data packets mapped with their processing nodes as mentioned in Table VIII:

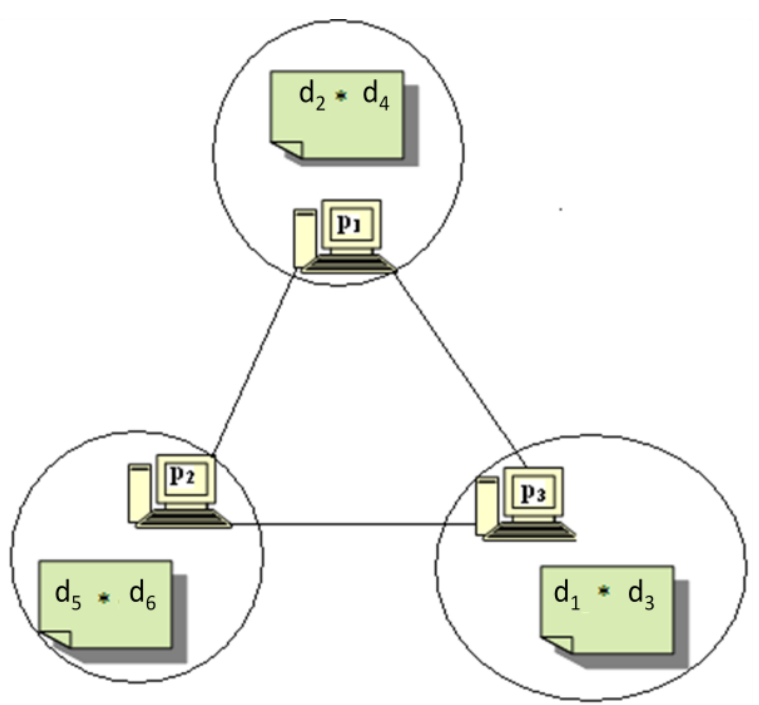

Fig. 3: Data packets routed to eligible processing nodes

Graphical representation of stated outcome of the given input as mentioned in Figure 3:

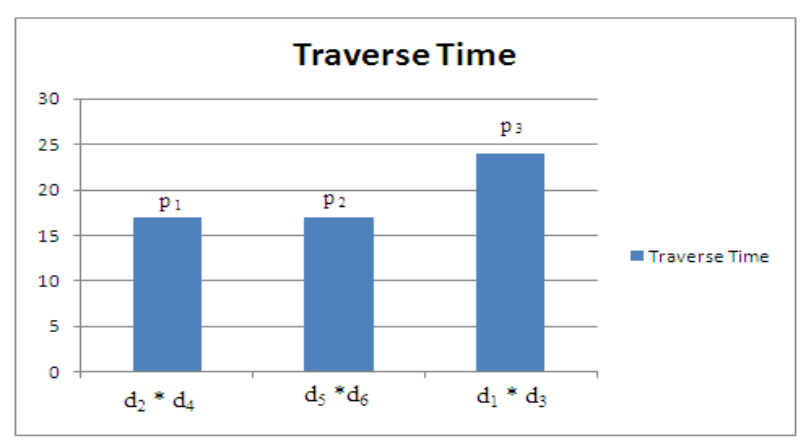

Fig 4: Shown Transmission time for data packets

This research paper calculates time complexity of the present algorithm as it is a major factor to show the performance of the algorithm. Present paper also contains the comparison between results with some other recent algorithm [14] for proving the betterment of the present algorithm as mentioned in Table IX.

\section{Table IX: Complexity comparison between present algorithm and algorithm [14]}

$\begin{array}{cccc}\begin{array}{c}\text { Number of } \\ \begin{array}{c}\text { Processors } \\ (\mathrm{n})\end{array}\end{array} & \begin{array}{c}\text { Number } \\ \text { of data } \\ \text { packets } \\ (\mathrm{m})\end{array} & \begin{array}{c}\text { Complexity of } \\ \text { algorithm }[14] \\ \mathrm{O}\left(\mathrm{n}^{2}\right)\end{array} & \begin{array}{c}\text { Complexity of } \\ \text { present } \\ \text { algorithm } \\ \text { O(mn) }\end{array} \\ 3 & 5 & 25 & 15 \\ 3 & 6 & 36 & 18 \\ 3 & 7 & 49 & 21 \\ 3 & 8 & 64 & 24 \\ 3 & 9 & 81 & 27 \\ 4 & 5 & 25 & 20 \\ 4 & 6 & 36 & 24 \\ 4 & 7 & 49 & 28 \\ 4 & 8 & 64 & 32 \\ 4 & 9 & 81 & 36 \\ 5 & 5 & 25 & 25 \\ 5 & 6 & 36 & 30 \\ 5 & 7 & 49 & 35 \\ 5 & 8 & 64 & 40 \\ 5 & 9 & 81 & 45\end{array}$


Figure 5, 6 and 7 demonstrate the time complexity comparison between the present algorithm and algorithm [14] for different values $m$ and $n$.

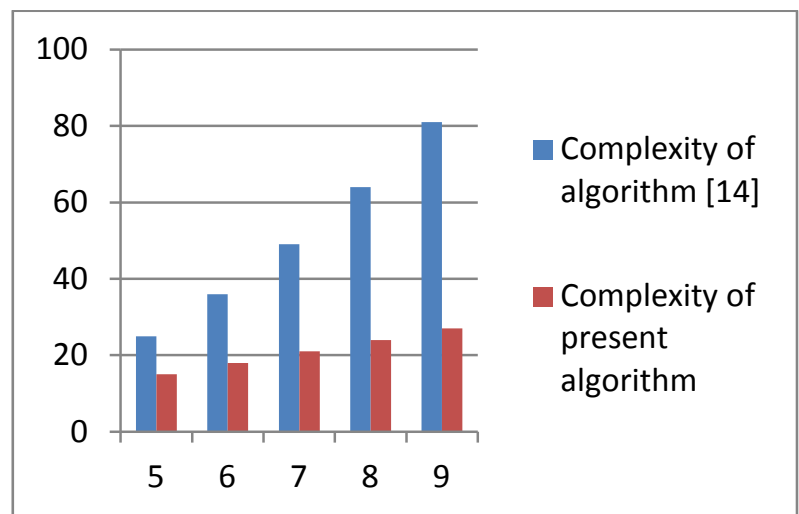

Figure 5: Number of Processors $=3$

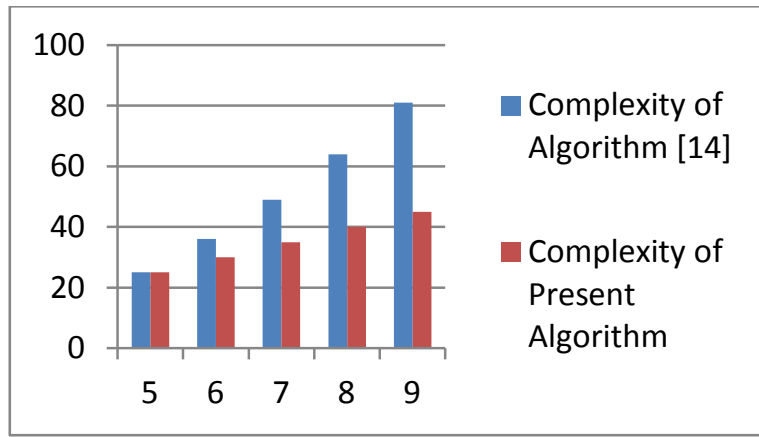

Figure 6: Number of Processors $=4$

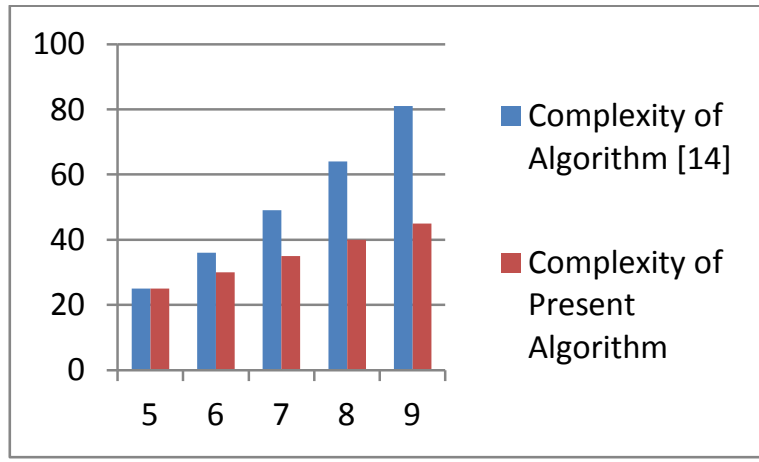

Figure 7: Number of Processors $=5$

\section{REFERENCES}

[1] Shajin Nargunam, M. P. Sebastian, "Hierarchical Multicast Routing Scheme for Mobile Ad Hoc Network", Vol. 4873, pp 464-475, 2007

[2] Abraham, C. Gavoille, A. V. Goldberg, D. Malkhi, "Routing in networks with low doubling dimension", In Proceedings of the 26th IEEE International Conference on Distributed Computing Systems (ICDCS), page 75, 2006

[3] Ashish Pandey, Md. Nasir Ahmed, Nilesh Kumar, P.Gupta, "A Hybrid Routing Scheme for Mobile Ad Hoc Networks with Mobile Backbones", High performance computing, Vol. 4297, 411-423, 2006
[4] BagerZarei, M.R. Meybodi, "A Hybrid method for Solving Traveling Salesman Problem", ICIS 2007, pp. 394-399, 2007

[5] Gavoille, M. Gengler, "Space-efficiency for routing schemes of stretch factor three", J. Parallel Distrib. Comput.", Vol. 61, issue 5, pp. 679-687, 2001

[6] Li, L. Li, "Utility-based scheduling for grid computing under constraints of energy budget and deadline", In: Comput. Stand. Inter, Vol. 31, Issue 6, pp. 1131-1142, 2009

[7] F. F. Dragan. "Estimating all pairs shortest paths in restricted graph families: a unified Approach", J. Algorithms, Vol. 57, issue 1, pp. 1-21, 2005

[8] F. Gonzalez-Castano, J. Vales-Alonso, M. Livny, "Condor grid computing from mobile handheld devices" ACM SIGMOBILE Mobile Computing and Communications Review, Vol. 7, Issue 1, pp 117-126, 2003

[9] Faizul Navi Khan, Kapil Govil, "Distributed Task Allocation Scheme for Performance Improvement in Mobile Computing Network", International Journal of Trends in Computer Science, Vol. 2 Issue 3, pp: 809-817, 2013

[10] H. Liu, T. Roeder, K. Walsh, R. Barr, E. G. Sire, "Design and implementation of a single system image operating system for ad hoc network", In: Proc. 3rd Int. Conference on Mobile Systems, Applications, and Services, pp. 149162, 6-8 June 2005

[11] Ioannis A Moschakis, Helen D Karatza , "Evaluation of gang scheduling performance and cost in a cloud computing system", Journal of Supercomputing, Vol. 59, Issue: 2, pp: 975-992, 2012

[12] J. Yang, Y. Bai, Y. Qiu, "A decentralized resource allocation policy in mini grid", In: Journal of Future Generation Computer Systems, Vol. 23, pp. 359-366, 2007

[13] K. A. Hummel, G. Jelleschitz, "Robust de-centralized job scheduling approach for mobile peers in ad hoc grid", In: 7th IEEE Int. Symp. on Cluster Computing and the Grid, pp. 461-470, 14-17 May 2007

[14] P. Ghosh, N. Roy, S. K. Das, "Mobility - aware efficient job scheduling in mobile grids", In: 7th IEEE Int. Symp. On Cluster Computing and the Grid, pp. 701-706, 14-17 May 2007

[15] Pankaj Saxena, Kapil Govil, "An Effective Reliability Efficient Algorithm for Enhancing the Overall Performance of Distributed Computing System", International Journal of Computer Applications, Vol. 82, Issue 5, pp 30-34, 2013

[16] R.K. Balan, M. Satyanarayanan, S.Y. Park, T. Okoshi, "Tactics-based remote execution for mobile computing". In: Proc. MobiSys 2003, 1st Conf. on Mobile Systems, Application and Services, pp. 273-286, 5-8 may 2003

[17] S. C. Shah, M.-S. Park, "An energy-efficient resource allocation scheme for mobile ad hoc computational grids", J. Grid Comput, Vol. 9, Issue 3, pp 303-323, 2011

[18] Sayed Chhattan Shah, Myong-Soon Park, Wan Sik Choi, Zeeshan Hameed Mir, Sajjad Hussain Chauhdary, Ali 
Kashif Bashir, Fida Hussain Chandio, "An Adaptive and Distance-based Resource Allocation Scheme for Interdependent Tasks in Mobile Ad Hoc Computational Grids", Informational Technology and Control, Vol. 41, Issue 4, pp. 307-315, 2012

[19] Tamar Eilam, Cyril Gavoille, David Peleg, "Average stretch analysis of compact routing schemes", Discrete
Applied Mathematics, Vol. 155, Issue 5, pp. 598-610, 2007

[20] Y. Dourisboure, "Compact routing schemes for generalisedchordal graphs", Journal of Graph Algorithms and Applications", Vol. 9, Issue 2, pp. 277-297, 2005 